\title{
Research on Education in Developing Countries: an inventory of Dutch projects and programmes
}

\author{
Paul Smits
}

\section{Background to the Survey}

This report is the product of an attempt to survey Dutch research in the area of education in developing countries and to present it in a comprehensive overview. The inventory includes not only ongoing research, but also research that has recently been concluded or is proposed.

'Research project' is taken here to mean relatively small-scale research that involves no more than four researchers. A 'research programme' is a collection of related projects, and involves five or more researchers. The borderline between these is not always perfectly clear; in some cases it must be drawn rather arbitrarily. The term 'research' is used in the broad sense, including in principle the whole range of research types, from fundamental to applied. What is important is that the research activities are substantial: the time devoted to them must be at least three months. Incidental research activities of short duration, such as ad hoc consultancy assignments, are not included in the inventory. Evaluation research is included, however, and is treated as a separate category, first because it has its own unique problems, and secondly, because it accounts for a relatively large share of educational research. Projects and programmes are classified as 'Dutch research' if the work is being done in whole or in part by researchers in the employ of universities or non-tuniversity research institutes in the Netherlands. Except for university theses, research done by individuals on their own is not included in the survey. On the other hand, when Dutch research institutes make a substantial contribution to the research programmes of international organisations, by providing either supervision or project workers, these international programmes are included.

'Education' is taken to mean all sorts of selfimprovement in addition to the transfer of knowledge and skills. It thus includes: i) formal education at all levels, from kindergarten to post-doctoral training;

ii) various forms of non-formal education. training and information, which exist for a wide variety of social purposes and target groups;

ii) informal education - that kind of learning which takes place outside the school or formal course.

Finally, the survey includes research on education 'in developing countries'. These are taken to be all the countries of Africa, Asia (with the exception of Japan), South and Central America, the Caribbean area and Oceania (except for Australia and New Zealand). Dutch international education is included in this category even though most of the courses are given in the Netherlands, since the courses are designed for and attended by people from the Third World.

\section{Organisation and Financing of Research Organisation of the research area}

In the Netherlands scientific and social scientific research is done by both university and non-university institutions. For university research, the basic unit is the vakgroep, which will be referred to here as 'department'. This is a group of people who give instruction and do research in a particular scientific field. Above this basic unit in the administrative structure of the university are two more levels: the faculty ('faculteit'), which represents the broader scientific discipline, and the board of governors and university council, which sit at the top of the pyramid.

As a separate field, 'education in developing countries' does not have an established place within any of the 13 Dutch universities. There is neither a department nor a professorial chair that bears this name. The researchers that work in this area are affiliated with other departments, where they often occupy rather isolated positions. What characterises this research area in the universities is how widely the researchers 
are spread over a great many institutions and departments throughout the country. In manpower terms, we are talking about a total of 19 specialised researchers. Most of them not only do research, however, but also have considerable obligations in terms of teaching and administration.

In general, the research that is done at places other than the universities is not fragmented in this way. In fact just the opposite is true. Researchers are largely concentrated within a single institute: the Centre for the Study of Education in Developing Countries (CESO). CESO is a specialised, interdisciplinary centre for teaching, research, consultancy and documentation in the area of education in developing countries. Its purpose is to make scientific and practical contributions which will help to improve that education. Within the Netherlands, CESO works with the universities and private and governmental bodies that are active in development cooperation. The centre has an important pivotal function in the network of researchers and organisations that concern themselves with educational issues in the developing countries. It has eight scientific staff members.

Another important body in organisational terms is the Research Association for Education in Developing Countries (WGOO). This is a national committee made up of university and non-university researchers in the area of education in developing countries. In principle, any interested parties are eligible to join this association. Its purpose is to improve the quality of research proposals, and to issue recommendations to the Dutch Organisation for Pure Scientific Research ( $Z W O$ ) concerning the financing of research projects from what is known as the 'second money flow' (see below). The committee also functions as a forum for the exchange of ideas and information, and as a meeting place for discussing research proposals and results with colleagues. Finally, the association plays an important role in helping to create a programmatic approach so that the various research projects in this area supplement rather than duplicate one another.

\section{Financing}

The Dutch system of research financing is generally thought of in terms of three 'money flows'. The government's direct financial support of the institutions where the research is done is called the 'first money flow'. Government funds that are channeled to researchers in the form of grants from $\mathrm{ZWO}$ are referred to as the 'second money flow'. The 'third money flow' is contract research: work is commissioned and financed by government bodies, industry, and private and international organisations.

With respect to financing within this system, the research area in question is no different from other areas. Both university and non-university development-related research on education is financed through these three channels.

A recent development that must be mentioned is the change now being made in the way university research is financed through the first money flow. In brief, this change means that a significant portion of the resources that are made available through this channel will no longer flow directly to the universities, but will now be subject to certain conditions. The term being applied to this is 'conditional financing'. To qualify for this form of financing, research programmes must be on the scale of at least five staff positions for a period of at least five years. The programmes must also be of high quality and with special social relevance.

The academic world has been particularly critical of the requirement in terms of scale. This is seen as detrimental to small scale research, which is thus cut off from a source of financing that will gradually lay claim to a larger portion of the financial resources. This poses a particular threat to research on education, which is marginal and most often small in scale. The only way to overcome this threat will probably be for individual researchers to join forces and submit joint, inter-university research programmes.

\section{Profile of Completed and Ongoing Research Research themes}

To give an impression of the themes of Dutch educational research, the individual projects and programmes have been grouped into seven thematic clusters - which are listed below, together with the number of projects (out of 38 ) in each group.

Functions of education (17) What these studies have in common is that they examine either the link between education and development, or the role and function of education in the development process. There are three sub-themes in this category: the relationship between education and development in general; education and rural development; and human resources (including the relationships between education, the labour market and employment).

Education as a system (5) The themes in this category are all related to administration, organisation, and management policy, including teacher training.

Education and culture (3) At issue here is the relationship between indigenous learning processes and forms of education that are introduced from outside. 
Comparative historical studies (6) This is comparative, historical-sociological research on the development of education.

Educational psychology studies (3) This is primarily research on the design and administration of tests for purpose of selection and placement.

Education and development cooperation (3) Research that is relevant to policy, in which educational cooperation with developing countries is of prime importance.

Education and the media (1) Research on how the media can be used for educational purposes.

As can be seen from this list, there tends to be a concentration around the theme 'functions of education'. In both absolute and relative terms, interest in this theme has increased over time. Interest is fairly evenly spread over the other themes, with the possible exception of comparative historical research, which has enjoyed continuous relatively high interest; and at the other end of the curve "education and the media', which is still quite new territory. It is interesting that there is a complete lack of studies with either a pedagogical or didactic orientation as such. This is even more surprising since research directed towards Dutch education concentrates so heavily on this theme. In view of the limitations of this classification scheme, however, it is possible that this kind of research is incorporated into other studies.

\section{Educational sectors}

How is the research distributed over the various types and sorts of education? The largest number of studies (14) deal with both formal and non-formal types of education. There are also four cases where the educational system as a whole is studied, rather than one or more specific sorts of education. Of the studies that are directed towards one sector, those on formal education are in the majority (12), followed by nonformal education (8). Informal education as a separate topic is still unexplored territory.

Within the sector of formal education, primary education is the most popular; interest in higher education is negligible. This is odd when one thinks that quite the opposite is true in the developing countries themselves. Comparing completed with ongoing research reveals that interest in formal education has waned, whereas interest in non-formal education is on the increase. This shift in emphasis most probably reflects the often heard plea that priority be given to non-formal education.

\section{Research regions}

On the regional distribution of the research, it is clear that research tends to be concentrated on two regions: sub-Saharan Africa and South and South East Asia. Within these large regions, there is a further degree of concentration on southern Africa (Zambia, Tanzania and Mozambique) and Indonesia. The latter is undoubtedly a function of the Netherlands' colonial past. These interests in terms of regions have been stable over time.

\section{Research types}

The research can be reduced to three categories on the basis of type: purely fundamental or theoretical, application-oriented, and research that is a combination of fundamental and applied. The scores are nearly equal for all three categories: 13,11 and 14 respectively.

Considering the fact that contract research accounts for only a small portion of the total, the proportion of applied studies can be seen as remarkably large. When viewed over time, however, there has been a slight decline in applied research, a shift that is quite the opposite of what one would expect nowadays.

\section{Financing}

For the description of research financing, the customary classification will be used: the first, second and third money flows. The greatest amount of financing support for development-related research on education ( 25 projects) is channelled through the first money flow - the regular budgets of the institutions. Contract research (the third money flow) is of limited importance, as is the second money flow from ZWO/WOTRO. It therefore seems that the correlation between research approach and source of financing is far less strong than the stereotype notions would lead us to expect.

The crude figures on financing do not, however, give an entirely accurate picture of reality. In fact there is a complex pattern of co-financing; one primary source always pays the largest share, usually including the costs of personnel, but extra funds are provided by one or more secondary source. The secondary sources are extremely important for research that is done overseas, since this always involves many additional costs.

\section{Cooperation}

The final aspect to be considered here is cooperation with institutions and researchers in the Third World. This is seen by many as extremely important, if for no other reason than to avoid the danger of academic colonialism. 
The questionnaire included several items that cast some light on the element of cooperation in the research on education, such as the question of who took the initiative for launching the research. The figures show clearly that in at least two cases out of three, the initiative came from the Dutch side - from the Dutch researchers and/or the departments or institutes they represent. In only six of the 38 cases was it the counterpart who took the initiative, and one could speak of a joint initiative in only two cases.

To what extent do the Dutch researchers actually work together with institutes and organisations in the Third World? It emerged that one or another form of cooperation with overseas partners is built into the research in more than two-thirds of the cases. This cooperation most often involves working with other research institutes or organisations. Far behind in second and third places are the categories 'government bodies' and 'multiple contacts'. Institutional cooperation has clearly increased over time, particularly with research institutes. It is interesting to note that there are hardly any cooperative ties with other western research institutes.

The data say nothing about what the cooperation involved in terms of transfer of knowledge, research training or strengthening of the local research capacity. It is not clear, for example, how much the local research institutes and researchers were actually involved in formulating and carrying out the research. The fact that more than two-thirds of the research projects and programmes were started at the initiative of Dutch researchers would suggest that the definition of the research problem is more likely to reflect the preoccupations and perceptions of the Dutch researchers than problems and needs as perceived in the developing country itself. The fact that research training and institutional strengthening were named as an explicit objective on only one questionnaire also creates some doubt about the level of cooperation.

\section{Evaluations of Private Educational Projects and Programmes}

In recent years there has been a great increase in research for evaluation purposes. This is undoubtedly due to the fact that this form of applied research is most directly linked to policy for Dutch development cooperation in the form of projects and programmes. These activities grew rapidly in the second half of the 1970s and the government wished to assess the results in order to help determine policy directions for the future and to improve the quality of the assistance given.

This increase in evaluation research can also be seen in the component of Dutch development cooperation that involves education. With an 11 per cent share of the funds for bilateral financial and technical 'public facilities' ( 35 per cent), 'agriculture' ( 24 per cent), and 'social infrastructure and welfare' (15 per cent).

In the technical assistance category in general, education was in first place with a 30 per cent share of the funds in 1980. Assistance in the form of technical training is often put in the hands of private, nongovernmental organisations. The government must make evaluations to see how its money is being spent, which explains why so much effort is expended on evaluating private projects and programmes that involve education and training.

Private cooperation with developing countries in the area of education generally falls within one of the following three broad programmes: The International Education Programme (IE Programme); The Programme for University Projects of Development Cooperation (PUO Programme); The Co-financing Programming (MFO Programme). The last includes more than just projects involving education, although if education is taken to include self-improvement, extension and staff training, it can be seen to account for a large portion of the projects in this programme.

\section{Evaluation research within the framework of the IE Programme}

The IE Programme is run by the 17 institutes in the Netherlands that offer practically oriented training at the post-secondary level to mid-career specialists from developing countries. Each year some 1,700 people come to the Netherlands to attend the various courses. International Education is also coming to include a growing number of education and training projects in the Third World itself, most of which are done in cooperation with local counterpart institutions.

The IE Programme has a long tradition of being evaluated; the first attempts date from the period between 1965 and 1969. Since that time various bodies and organisations, including CESO, FAO and DHV, have worked on setting up a more permanent evaluation structure. This resulted in what is known as the EPIO Programme: the Evaluation Programme for International Education, which got underway in 1981 and will be concluded in mid- 1984 .

EPIO has a three-fold purpose:

- to evaluate the IE Programme;

- to set up a standardised system of self-evaluation for all the IE institutes and for the regional projects with which they are involved in the Third World;

- to issue recommendations concerning a permanent organisational structure for evaluating the IE Programme. 
What follows are some examples of the typical problems that can be encountered in the process of doing research for evaluation purposes [van Ravenswailij and van Holsteijn 1983].

The problem of multiple roles In practice, the multiple objective presents the evaluation team with many problems. Combining $a$ and $b$ is particularly difficult: it is hard to assess the programme objectively while at the same time being helpful in setting up a built-in evaluation system. Task a requires distance from the individuals involved; task $b$ requires involvement and trust. The evaluator is put in a difficult position because he is torn between roles that are mutually exclusive in principle. Tension and a lack of trust result.

Technical research problems These problems stem from the heterogencous nature of the research population - the alumni of International Education, who are from many different developing countries - and are in fact the same problems that are inherent in all cross-cultural research. Differences between the respondents in terms of cultural background and language produce spurious differences in the results that must be eliminated systematically for the sake of reliability.

The influence of external, political factors Evaluation reports can play an important role in the political negotiating process to determine whether or not whole programmes or components of development programmes will be continued or not. This means that evaluation research is extremely vulnerable to political influence; it is natural for the parties concerned to try to influence the research results in a direction that is favourable to them.

\section{Evaluation research within the framework of the Programme for University Projects of Develop- ment Cooperation (PUO Programme)}

The PUO Programme is maniged by the Netherlands Universities Foundation for International Cooperation (NUFFIC) and carried out by the Dutch universities in cooperation with counterpart institutions overseas. The purpose of the programme is to lend support to the building up and strengthening of institutions of higher education in developing countries. Long term cooperative links are established between institutions. These generally include projects in more than one area of specialisation. At the moment the programme consists of nine interuniversity cooperative links and three pilot projects.

CESO was asked by the NUFFIC board to make an evaluation of the whole programme during the period from 1976 to 1978 . This resulted in eight reports. This evaluation was made when PUO was still made up of many separate projects rather than being concentrated into broad, long term cooperative links. For the new style of PUO, a detailed evaluation system was developed which has two main characteristics:

- evaluation at various stages: during the preparatory phase (the 'ex-ante evaluation'), while projects are in progress (monitoring), and after activities have been concluded ('ex-post evaluation');

- evaluation at various levels: at the level of the project, the cooperative link, and the programme als a whole.

The keystone in the evaluation process is the periodic external evaluation of the cooperative links. This involves a penetrating analysis and assessment of the activities carried out up to the time of the evaluation. Emphasis is on the impact and effectiveness of the cooperation, and what the activities are achieving in terms of the goals of the PUO programme. The external evaluators' report plays an important role in the final decisions as to whether a cooperative link will be continued or not. In putting together a team of evaluators, an attempt is always made to recruit at least one of the members from the developing country or region in question. The external evaluation reports follow a protocol to facilitate comparison. This is particularly helpful when it comes time to evaluating the programme as a whole, since it is the evaluations of the cooperative links that form the basis of the more general evaluation.

\section{Evaluation research within the framework of the Co-financing Programme (MFO Programme)}

The MFO Programme is managed by what are called the co-financing organisations: CEBEMO, ICCO NOVIB and HIVOS. These non-government organisations maintain intensive contacts with the counterpart organisations overseas who act ually carry out the projects for the benefit of the target groups. The policy of the co-financing organisations causes them to concentrate on the consciousness-raising, emancipation and participation of groups at the bottom of society. This orientation is clearly reflected in the projects that are chosen for support. There is a leaning towards projects that aim to strengthen the population socially and politically through education, extension and job training.

Despite some differences of approach among these four private organisations, their evaluation research shares the following general characteristics:

- Evaluation research is seen not only as an instrument for improving the quality of the help, but also as an instrument for achieving relations that place the co-financing organisations and their 
counterparts overseas on a more equal footing. The research is thus always a joint responsibility of the two partners.

- The research is generally brief in character (taking no longer than one month) and standardised so that it can be repeated easily. The evaluation is more often ex-post than ex-ante. It follows activities more often than it precedes them.

- There is a development in the direction of a process approach, in which evaluation becomes a built-in, more or less continuous activity, rather than the frozen-action impression that is provided by external evaluations. This development is running parallel with a shift from external evaluation to internal or self-evaluation. The greater emphasis on the latter is based on both theoretical and practical considerations. Theoretically, selfevaluation is consistent with the policy objectives of the co-financing organisations, such as the active participation of the target group, partnership, and authentic development. By contrast, external evaluation tends to highlight the relationship of dependence on the donor organisation. The practical arguments favouring self-evaluation are related to the evaluation's follow-up - the likelihood that the recommendations will indeed be implemented. When the target group itself is making the recommendations, the chance is much greater. Self-evaluation is considered important because it can make an important contribution both to the 'decolonisation' of development cooperation and to the 'democratisation' of the development process [van Duin and van Soest 1983].

- The link between evaluation activities and policy generally leaves a great deal to be desired Relatively little attention is given to summarising the research findings and presenting them in a form that can be translated into policy. This is due largely to the limited institutional capacity [Streefland 1982].

- Local research institutes and researchers are involved in the research as much as possible, not only for the purpose of transferring knowledge and training local researchers, but also for the purpose of building up a world wide network.

\section{Bottlenecks}

What 'bottlenecks' have hampered the progress of the research in its various stages? The answers to this question have been placed into categories. Within each category a distinction is drawn between the phases of the research process, ie preparation, implementation and reporting.
There are basically four groups of problems, which can be described briefly as follows:

Financing This is undoubtedly one of the most pressing problems, given the prospects of continued austerity and the reallocation of government funds for scientific research. The problem does not so much involve basic research costs (salaries, etc) as it does finding funds for the extra costs that are specific to doing research abroad, for example the costs of factfinding missions and presenting and publishing the research results in two places and two languages.

Problems of methodology and research techniques Problems can arise when the theoretical orientation and the research design are translated into concrete research questions and instruments. Communication with the counterpart and/or the sponsor can break down and frictions arise. Radical alterations in research techniques may also be called for when the local circumstances deviate too much from the original research design.

Research environment The research is often done in a politically sensitive situation that is characterised by rapid change. Political instability and the circulation of political and bureaucratic elites can slow down the progress of the research. Bureaucratic obstacles and the simple logistics of housing, transport and supplies can also create problems.

Communication The distances involved create communication problems. During the preparatory stages correspondence with the counterpart or potential counterpart can be unsatisfactory and involve long delays. Researchers also have problems during the implementation phase when support from back home is inadequate or slow.

\section{Research Agenda}

On the agenda of development-related research on education, what is it that stands out in the Netherlands? What are the themes of the planned research activities, and which educational sectors and regions are to be covered?

A total of 10 research projects have been proposed. Once again, we see strong concentration around the theme 'functions of education' (seven projects) and within this around the sub-theme 'human resources' (4). Studies on education and rural development, however, are becoming increasingly concentrated on the sub-theme of food production. It is interesting to note the complete absence of proposed research activities in the area of education, telecommunication and information science, even though this topic is very popular at the moment and certainly can be very important for the developing countries. 
The planned research activities are not specifically aimed at one particular sector, but rather at various types of formal and non-formal education, at combinations of the two, and at the education system as a whole. The same is true for the distribution of the planned research over regions; there is no particular concentration. With respect to the various research approaches, there seems to be a clear preference for a mixed approach (seven of the 10 cases). Only one case can be seen as purely fundamental, and only two as purely applied.

Finally, there is the aspect of cooperation with the overseas partners. In eight of the 10 studies proposed, mention is made of a potential cooperative link with an overseas counterpart. Four of these are research institutes or organisations. At the same time, the initiative for cooperation still tends to come from the
Dutch side. In only one case was it the counterpart who took the initiative, and two cases can be seen as joint initiatives.

\section{References}

Streefland, P., 1982, 'Het evalueren van ontwikkelingsprojecten' ('The evaluation of development projects'), Internationale Spectator, December

van Duin, J. and J. van Soest, 1983, 'Evaluatie en beleidsontwikkeling bij intermediaire organisaties' ('Evaluation and policy development in intermediary organisations'), paper presented at a study day on evaluation, Free University of Amsterdam

van Ravenswaaij, B. and H. van Holsteijn, 1983, 'Evaluatie van internationaal onderwijs: enkele probleemgebieden', paper presented at a study day on evaluation, Free University of Amsterdam 